\title{
Genetic diversity of the endangered scaly-sided merganser (Mergus squamatus) in the wintering habitat of central-southern China
}

\author{
Z.-Q. Zhang ${ }^{1 *}$, C.-J. Qin ${ }^{2 *}$, D.-A. Fang ${ }^{3 *}$, A.-P. Wang ${ }^{1}$ and C.-H. Luo ${ }^{1}$ \\ and $\mathrm{K} . \mathrm{Liu}^{3}$ \\ ${ }^{1}$ School of Life Sciences, Shangrao Normal University, Shangrao, China \\ ${ }^{2}$ School of Life Sciences, Neijiang Normal University, Neijiang, China \\ ${ }^{3}$ Freshwater Fisheries Research Center, Chinese Academy of Fishery Sciences, \\ Wuxi, China \\ *These authors contributed equally to this study. \\ Corresponding author: D.-A. Fang \\ E-mail: fangdyan@gmail.com
}

Genet. Mol. Res. 12 (3): 3103-3109 (2013)

Received July 24, 2012

Accepted February 2, 2013

Published April 26, 2013

DOI http://dx.doi.org/10.4238/2013.April.26.2

\begin{abstract}
The scaly-sided merganser (Mergus squamatus), found in temperate East Asia, has been reduced to a very small population. Central and southern China are its main wintering habitat. However, populations have declined greatly since the 1980s due to habitat loss and degradation, and poaching. To meet the urgent need for up-to-date conservation information, we examined RAPD DNA markers from 156 specimens in 6 populations in Jiangxi Province. We found that genetic diversity (based on individual similarities) is in fact low; molecular variance between populations ranged from 0.137 to 0.347 . Genetic similarity ranged from 0.683 to 0.866 . In conclusion, the geographical pattern of genetic diversity supports the long-term refugial status of the scaly-sided merganser in central-southern China; strong conservation measures should be taken to maintain the merganser in this region.
\end{abstract}

Key words: Genetic diversity; Mergus squamatus; Wintering habitat; Endangered species 


\section{INTRODUCTION}

Genetic diversity is a fundamental component of biodiversity and is closely related to the geographic distribution of genotypes that constitute subspecies, races, or ecotypes (Sreekumar and Renuka, 2006). Studies of the spatial distribution of genetic variation within and between populations, or population genetic structure, have greatly facilitated our understanding of speciation, adaptation, and population dynamics. The population genetic structure of a species can be influenced by many factors (Allnutt et al., 2003). Surveys of genetic diversity are an important step toward inferring biological parameters, especially for species that have been little studied, have small or threatened population distributions, and are of concern for conservationists (Kuro-o et al., 2010; Miller et al., 2010). In particular, single marker studies offer a quick and inexpensive method to detect genetic patterns that can direct subsequent research of species and populations via molecular and field research.

The scaly-sided merganser (Mergus squamatus) breeds in southeast Russia, northeast China, and North Korea (Figure 1) and is one of the most threatened duck species (Liu et al., 2010). It is listed as 'endangered' by the International Union on the Conservation of Nature (IUCN, 2008), 'rare' in the Red Data Book of the Russian Federation (Iliashenko and Iliashenko, 2000), and in the first rank category of the List of the Protected Wildlife of National Importance in China (Collar et al., 1994; Pearce et al., 2009). World population estimates vary from 2400 to 10,000 individuals (He et al., 2002; Solovieva et al., 2006; Pearce and Petersen, 2009); approximately $80 \%$ of the wintering population is thought to winter in central-southern China, including Jiangxi Province (Solovieva et al., 2006; Liu et al., 2010).

Random amplified polymorphic DNA (RAPD) markers have been widely applied in population genetics (Lynch and Milligan, 1994; Perez et al., 1998). RAPD analysis has been used to investigate the genetic diversity and structure of populations of rare and endangered plant species (Fischer et al., 2000). Recent comparative studies of allozymes showed that RAPDs and AFLPs (Sun and Wong, 2001) have similar analytical efficiency as markers for a population genetic study, suggesting that RAPDs could still be used as reliable markers under well-controlled laboratory conditions. We assessed the genetic diversity of the endangered scaly-sided merganser in the wintering habitat of the central-southern area of China using RAPD analysis. The RAPD data were used to determine the influence of the founder effect on genetic diversity in this migrant population.

\section{MATERIAL AND METHODS}

\section{Sample collection and DNA extraction}

Feathers were collected from M. squamatus in the central-southern area of China $(\mathrm{N}=156)$ mainly in Jiangxi Province (YiYang Qinghu River = YYQ; FuLiang River = FLR; XiuShui River $=$ XSR; WuYuan Lean $=$ WYL; YingTan Longhu $=$ YTL; QingAn River = QAR; Table 1 and Figure 1). Feathers were stored on silica gel. DNA was extracted using protocols described in Talbot et al. (2011). 
Table 1. Populations of endangered scaly-sided merganser sampled for RAPD analysis.

\begin{tabular}{lccl}
\hline Population locality & Abbreviation & Sample size & Position \\
\hline YiYang Qinghu & YYQ & 32 & $28^{\circ} 3^{\prime} \mathrm{N}, 117^{\circ} 13^{\prime} \mathrm{E}$ \\
FuLiang River & FLR & 23 & $29^{\circ} 32^{\prime} \mathrm{N}, 117^{\circ} 23^{\prime} \mathrm{E}$ \\
XiuShui River & XSR & 58 & $28^{\circ} 57^{\prime} \mathrm{N}, 114^{\circ} 45^{\prime} \mathrm{E}$ \\
WuYuan Lean & WYL & 15 & $28^{\circ} 68^{\prime} \mathrm{N}, 116^{\circ} 76^{\prime} \mathrm{E}$ \\
YingTan Longhu & YTL & 16 & $28^{\circ} 12^{\prime} \mathrm{N}, 116^{\circ} 96^{\prime} \mathrm{E}$ \\
QingAn River & QAR & 12 & $28^{\circ} 86^{\prime} \mathrm{N}, 115^{\circ} 33^{\prime} \mathrm{E}$ \\
\hline
\end{tabular}

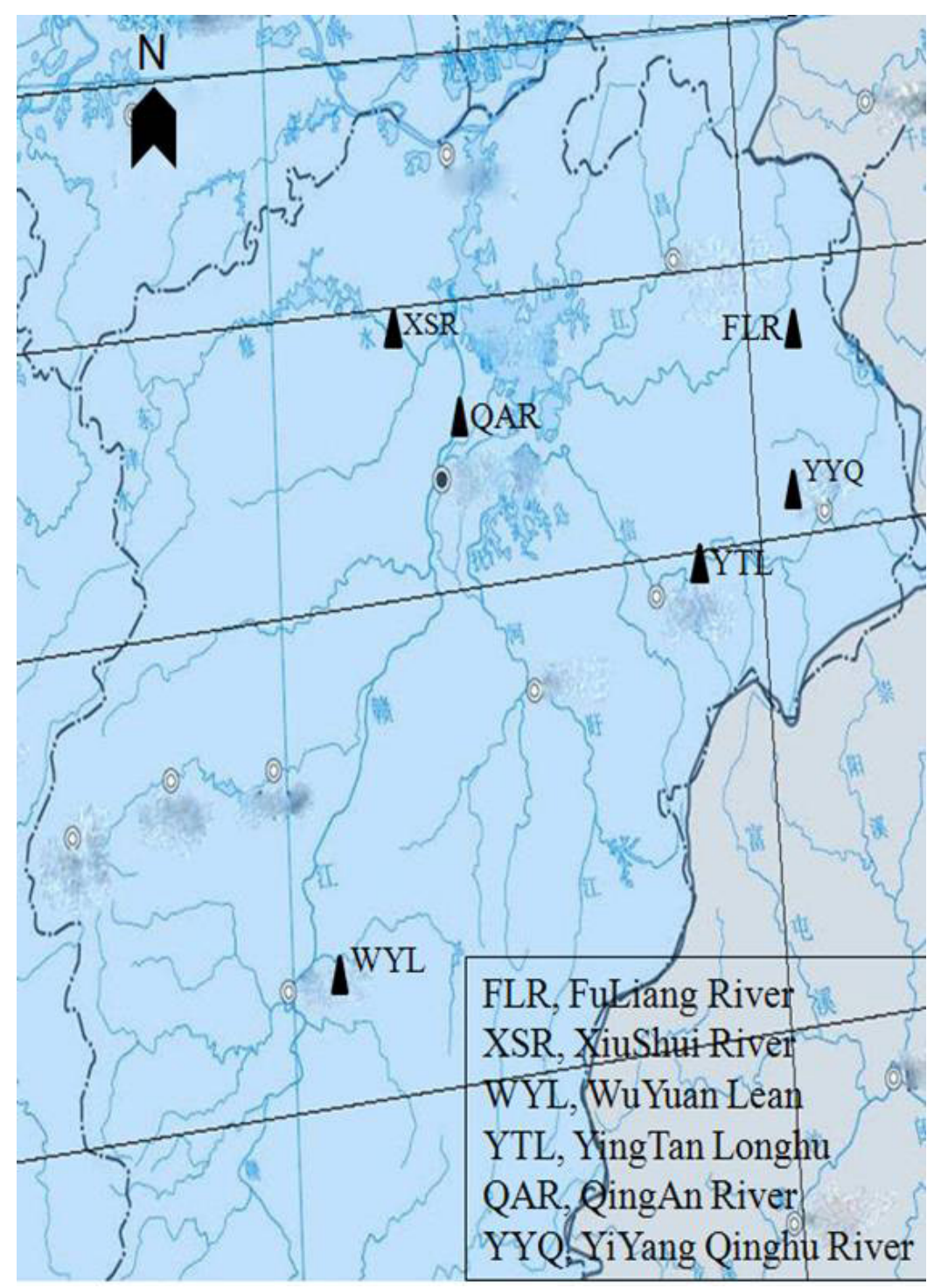

Figure 1. Distribution of 6 populations of endangered scaly-sided merganser sampled in this study. 


\section{RAPD amplification}

Forty-eight RAPD primers were initially screened using a subset of DNA samples representing the different populations. A negative control reaction containing all PCR constituents, except template DNA, was used to verify that no self-amplification or DNA contamination occurred. Each primer was assessed based on the quality of the amplified product. Only primers producing consistent amplification with well-defined, brightly staining bands were used in further amplifications of DNA from all individuals (Table 2). Amplifications were repeated to ensure reproducibility of the products scored. RAPD markers were scored for presence/absence, and each marker was identified by primer and marker size.

\section{Analysis of genetic diversity}

Assumptions associated with RAPD marker analysis were made as described by Lynch and Milligan (1994). Genetic similarity between individuals was estimated using the similarity coefficient of Nei and Li (1979). We used the UPGMA (unweighted pair-group method with arithmetic mean) to illustrate the genetic relationships between individuals within a single population and between populations.

\section{RESULTS AND DISCUSSION}

\section{RAPD results}

Of the 48 primers tested, 16 yielded a high number of reproducible amplification products; these were used in all sample testing. Amplification products ranged from 3 to 9 markers per primer (Table 2), resulting in 104 total genetic markers from all sampled individuals. Amplification product sizes were $0.35-2.5 \mathrm{~kb}$. The calculated polymorphic rate was from 36.4 to $72.7 \%$. Thus, the primers amplified a sufficient number of bands to distinguish between populations and estimate genetic diversity in each population.

Table 2. Attributes of primers used for RAPD analysis from 156 feathers of endangered scaly-sided merganser
sampled from 6 populations.
\begin{tabular}{llcccc}
\hline Primer & Sequence (5'-3') & No. of bands scored & No. of PB & PPB (\%) & Approx. band size range (bp) \\
\hline OPA-02 & TGCCGAGCTG & 11 & 8 & 0.727 & $500-1300$ \\
OPA-07 & GAAACGGGTG & 13 & 7 & 0.538 & $450-2000$ \\
OPA-08 & GTGACGTAGG & 17 & 9 & 0.529 & $550-2000$ \\
OPA-11 & CAATCGCCGT & 13 & 8 & 0.615 & $500-1500$ \\
OPB-14 & TCCGCTCTGG & 15 & 7 & 0.467 & $450-2000$ \\
OPB-15 & GGAGGGTGTT & 11 & 7 & 0.636 & $350-1500$ \\
OPD-07 & TTGGCACGGG & 14 & 6 & 0.429 & $400-2500$ \\
OPD-07 & TTGGCACGGG & 12 & 6 & 0.417 & $600-2000$ \\
OPE-04 & GTGACATGCC & 11 & 4 & 0.545 & $600-2000$ \\
OPG-05 & CTGAGACGGA & 11 & 7 & 0.364 & $500-1750$ \\
OPG-10 & AGGGCCGTCT & 8 & 8 & 0.538 & $550-1500$ \\
OPP-11 & AACGCGTCGG & 13 & 7 & 0.615 & $600-2000$ \\
OPP-14 & CCAGCCGAAC & 13 & 4 & 0.636 & $500-2500$ \\
OPJ-15 & TGTAGCAGGG & 11 & 8 & 0.571 & $650-1750$ \\
OPM-12 & GGGACGTTGG & 7 & 0.615 & $650-1750$ \\
OPT-18 & GATGCCAGAC & 13 & $500-2000$ \\
\hline
\end{tabular}

$\mathrm{PB}=$ polymorphic bands; $\mathrm{PPB}=$ percentage of polymorphic locus bands. 


\section{Genetic similarity within and between populations}

The highest levels of genetic similarity were generally found between individuals from the same population (Table 3). Average genetic similarities within populations were higher than between populations. The within-population similarity index ranked as FLR $(91.2 \%)>$ YYQ $(89.6 \%)>$ WYL $(88.6 \%)>$ QAR $(86.8 \%)>$ YTL $(85.3 \%)>$ XSR $(84.6 \%)$, and there was no difference between populations. Further, the inter-population similarity was highest between XSR and YTL (86.6\%), and lowest between WYL and QAR (68.3\%). The genetic distance was lowest between XSR and YTL (14.6\%), and highest between WYL and QAR (34.7\%). The 6 populations sampled ranged in similarity from 68.3 to $86.6 \%$, indicating that the wintering population has low genetic diversity and low hereditary variation.

\begin{tabular}{|c|c|c|c|c|c|c|}
\hline Populations & YYQ & FLR & XSR & WYL & YTL & QAR \\
\hline YYQ & - & 0.783 & 0.845 & 0.826 & 0.764 & 0.793 \\
\hline FLR & 0.232 & - & 0.756 & 0.823 & 0.796 & 0.847 \\
\hline XSR & 0.163 & 0.158 & - & 0.735 & 0.866 & 0.726 \\
\hline WYL & 0.157 & 0.176 & 0.137 & - & 0.812 & 0.683 \\
\hline YTL & 0.208 & 0.226 & 0.146 & 0.184 & . & 0.842 \\
\hline QAR & 0.269 & 0.168 & 0.192 & 0.347 & 0.171 & - \\
\hline
\end{tabular}

Numbers in the upper right and the lower left of the matrix indicate genetic similarity and distance among 6 populations, respectively. For abbreviations, see Table 1.

Reductions in genetic diversity were similar to that reported from other recently established populations (Pascual et al., 2001) and are suggestive of a single (or rapid) colonization of the habitats, as sequential colonization would likely have maintained similar levels of genetic diversity between populations from different habitats. Thus, several populations that have been established for longer periods show smaller reductions in genetic diversity indices. These studies illustrate the strength of founder events and genetic drift on the spatial distribution of allelic frequencies as genetic differentiation was observed between the source and colonizing populations within very few generations.

\section{Population cluster analysis}

Analyses of the 6 populations sampled using cluster analysis (Figure 2) demonstrated 6 distinctive groups corresponding to the different winter habitats from which feathers were collected. The UPGMA and neighbor-joining method also indicated that these 6 populations share high genetic similarity, highest for XSR and YTL (86.6\%), and lowest between WYL and QAR (68.3\%). The genetic distance was lowest between XSR and YTL (14.6\%), and highest between WYL and QAR (34.7\%).

Populations from separate wintering habitats were clearly distinct and demonstrated a high within-habitat level of genetic similarity. These tendencies suggest a correlation between genetic distance and geographic distribution between habitats. Habitat populations also showed biogeographic distributional trends, such that XSR was more similar to QAR, YYQ was more similar to YTL, and FLR was intermediate, consistent with progressive dispersal across the wintering habitat. 


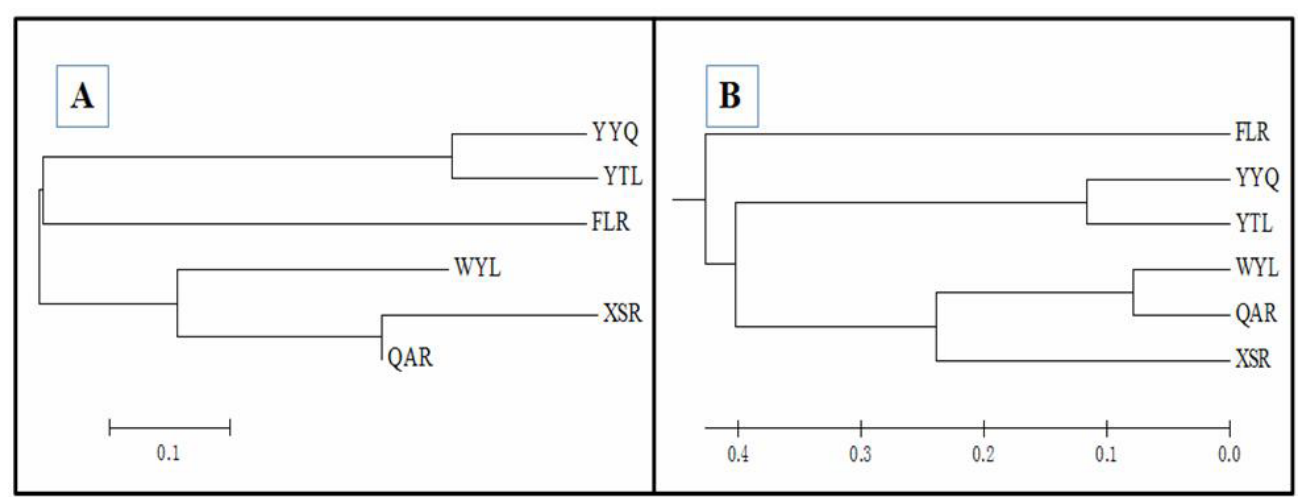

Figure 2. Neighbor-joining (NJ) and unweighted pair-group method with arithmetic mean average (UPGMA) dendrogram based on Nei's (1972) genetic distance between the populations of endangered scaly-sided merganser sampled in this study. A. NJ method. B. UPGMA method using MEGA 4.0. For abbreviations, see Table 1.

Scaly-sided merganser wintering in China are widely distributed and at low densities (He et al., 2002). Future research efforts based on our genetic diversity findings should include targeting a larger proportion of the population for DNA sampling to improve characterization of molecular diversity and population dynamics.

\section{ACKNOWLEDGMENTS}

Research supported by grants from the Jiangxi Education Foundation Program (\#GJJ11233), the Shangrao Normal University fund for the young teacher, and the Nature Science Youth Foundation of Jiangsu Province (\#BK2012093).

\section{REFERENCES}

Allnutt TR, Newton AC, Premoli A and Lara A (2003). Genetic variation in the threatened South American conifer Pilgerodendron uviferum (Cupressaceae), detected using RAPD markers. Biol. Conserv. 114: 245-253.

Collar NJ, Crosby MJ and Stattersfield AJ (1994). Birds to Watch 2: The World Checklist of Threatened Birds. BirdLife International, Cambridge.

Fischer M, Husi R, Prati D, Peintinger M, et al. (2000). RAPD variation among and within small and large populations of the rare clonal plant Ranunculus reptans (Ranunculaceae). Am. J. Bot. 87: 1128-1137.

He FQ, Melville D, Gui XJ, Hong YH, et al. (2002). Status of the scaly-sided merganser wintering in mainland China in the 1990's. Waterbirds 25: 462-464.

Iliashenko VY and Iliashenko EI (2000). Krasnaya Kniga Rossii: Pravovye Akty (Red Data Book of Russia: Legislative Scts). State Committee of the Russian Federation for Environmental Protection, Moscow, 143.

IUCN (2008). 2008 IUCN Red List of Threatened Species. Available at [http://www.iucnredlist.org]. Accessed June 22, 2010.

Kuro-o M, Yonekawa H, Saito S, Eda M, et al. (2010). Unexpectedly high genetic diversity of mtDNA control region through severe bottleneck in vulnerable albatross Phoebastria albatrus. Conserv. Genet. 11: 127-137.

Liu P, Li F, Song H, Wang Q, et al. (2010). A survey to the distribution of the scaly-sided Merganser (Mergus squamatus) in Changbai mountain range (China side). Chin. Birds 1: 148-155.

Lynch M and Milligan BG (1994). Analysis of population genetic structure with RAPD markers. Mol. Ecol. 3: 91-99.

Miller MJ, Bermingham E, Klicka J, Escalante P, et al. (2010). Neotropical birds show a humped distribution of withinpopulation genetic diversity along a latitudinal transect. Ecol. Lett. 13: 576-586. 
Nei M and Li WH (1979). Mathematical model for studying genetic variation in terms of restriction endonucleases. Proc. Natl. Acad. Sci. U. S. A. 76: 5269-5273.

Pascual M, Aquadro CF, Soto V and Serra L (2001). Microsatellite variation in colonizing and palearctic populations of Drosophila subobscura. Mol. Biol. Evol. 18: 731-740.

Pearce JM and Petersen MR (2009). Post-fledging movements of juvenile common mergansers (Mergus merganser) in Alaska as inferred by satellite telemetry. Waterbirds 32: 133-137.

Pearce JM, McCracken KG, Christensen TK and Zhuravlev YN (2009). Migratory patterns and population structure among breeding and wintering red-breasted mergansers (Mergus serrator) and common mergansers (M. merganser). Auk 126: 784-798.

Perez T, Albornoz J and Dominguez A (1998). An evaluation of RAPD fragment reproducibility and nature. Mol. Ecol. 7: $1347-1357$.

Solovieva D, Shokhrin V, Vartanyan S, Dondua A, et al. (2006). Scaly-sided Merganser surveys in Primorye, Russia, 2003-05. Threat Waterfowl Specialist Group News 15: 60-69.

Sreekumar VB and Renuka C (2006). Assessment of genetic diversity in Calamus thwaitesii BECC. (Arecaceae) using RAPD markers. Biochem. Syst. Ecol. 34: 397-405.

Sun M and Wong KC (2001). Genetic structure of three orchid species with contrasting breeding systems using RAPD and allozyme markers. Am. J. Bot. 88: 2180-2188.

Talbot SL, Palmer AG, Sage GK, Sonsthagen SA, et al. (2011). Lack of genetic polymorphism among peregrine falcons Falco peregrinus of Fiji. Biol. Conserv. 42: 415-428. 